Check for updates

Cite this: Chem. Sci., 2018, 9, 2831

\title{
Insertion, protonolysis and photolysis reactivity of a thorium monoalkyl amidinate complex $\dagger$
}

\begin{abstract}
Nicholas S. Settineri (D) ab and John Arnold (D)*ab
The reactivity of the thorium monoalkyl complex $\mathrm{Th}\left(\mathrm{CH}_{2} \mathrm{SiMe}_{3}\right)(\mathrm{BIMA})_{3}\left[1, \mathrm{BIMA}=\mathrm{MeC}\left(\mathrm{N}^{\mathrm{i} P r}\right)_{2}\right]$ with various small molecules is described. While steric congestion prohibits the insertion of $N, N^{\prime}$ diisopropylcarbodiimide into the $\mathrm{Th}-\mathrm{C}$ bond in 1 , the first thorium tetrakis(amidinate) complex, $\mathrm{Th}(\mathrm{BIMA})_{4}(2)$, is synthesized via an alternative salt metathesis route. Insertion of $p$-tolyl azide leads to the triazenido complex Th[(p-tolyl) $\left.N N N\left(C_{2} \mathrm{SiMe}_{3}\right)-\kappa^{2} \mathrm{~N}^{1,2}\right](\mathrm{BIMA})_{3}$ (3), which then undergoes thermal decomposition to the amido species $\operatorname{Th}\left[\left(p\right.\right.$-tolyl) $\left.\mathrm{N}\left(\mathrm{SiMe}_{3}\right)\right](\mathrm{BIMA})_{3}$ (4). The reaction of 1 with 2,6dimethylphenylisocyanide results in the thorium iminoacyl complex $\operatorname{Th}\left[\eta^{2}-(\mathrm{C}=\mathrm{N})-2,6-\mathrm{Me}_{2^{-}}\right.$ $\left.\mathrm{C}_{6} \mathrm{H}_{3}\left(\mathrm{CH}_{2} \mathrm{SiMe}_{3}\right)\right](\mathrm{BIMA})_{3}(5)$, while the reaction with isoelectronic $\mathrm{CO}$ leads to the products $\mathrm{Th}[\mathrm{OC}(=$ $\left.\left.\mathrm{CH}_{2}\right) \mathrm{SiMe}_{3}\right](\mathrm{BIMA})_{3}(6)$ and $\mathrm{Th}\left[\mathrm{OC}\left(\mathrm{N}^{\prime} \mathrm{Pr}\right) \mathrm{C}\left(\mathrm{CH}_{2} \mathrm{SiMe}_{3}\right)\left(\mathrm{C}(\mathrm{Me}) \mathrm{N}\left({ }^{\prime} \mathrm{Pr}\right)\right) \mathrm{O}-\kappa^{2} \mathrm{O}, \mathrm{O}^{\prime}\right](\mathrm{BIMA})_{2}$ (7), the latter being the result of $\mathrm{CO}$ coupling and insertion into an amidinate ligand. Protonolysis is achieved with several substrates, producing amido (9), aryloxide (10), phosphido (11a,b), acetylide (12), and cationic (13) complexes. Ligand exchange with 9-borabicyclo[3.3.1]nonane (9-BBN) results in formation of the thorium borohydride complex $(\mathrm{BIMA})_{3} \mathrm{Th}(\mu-\mathrm{H})_{2}\left[\mathrm{~B}\left(\mathrm{C}_{8} \mathrm{H}_{14}\right)\right]$ (14). Complex 1 also reacts under photolytic conditions to eliminate $\mathrm{SiMe}_{4}$ and produce Th(BIMA) $)_{2}\left(\mathrm{BIMA}{ }^{*}\right)\left[15, \mathrm{BIMA} *\left({ }^{i} \mathrm{Pr}\right) \mathrm{NC}\left(\mathrm{CH}_{2}\right) \mathrm{N}\left({ }^{i} \mathrm{Pr}\right)\right]$, featuring a rare example of a dianionic amidinate ligand. Complexes 2, 3, 5, 6, 11a, and 12-15 were characterized by ${ }^{1} \mathrm{H}$ and ${ }^{13} \mathrm{C}\left\{{ }^{1} \mathrm{H}\right\}$ NMR spectroscopy, FTIR, EA, melting point and X-ray crystallography. All other complexes were identified by one or more of these spectroscopic techniques.
\end{abstract}

Received 16th December 2017 Accepted 9th February 2018

DOI: $10.1039 / \mathrm{c} 7 \mathrm{sc} 05328 \mathrm{~b}$

rsc.li/chemical-science regarding thorium organometallic species bearing carbocyclic ancillary ligands $\left(\mathrm{C}_{5} \mathrm{R}_{5}\right),{ }^{9-15}$ and many groups have continued to explore the reactivity of these systems. ${ }^{16-20}$ Others have turned to non-carbocyclic ligands, in an attempt to investigate how complex stability and reactivity is affected by modifying the steric and electronic properties of the ancillary ligand framework..$^{21-28}$ Having used a variety of non-carbocyclic ligand frameworks to stabilize and the explore the reactivity of both transition metal and actinide complexes, ${ }^{29-34}$ our group endeavored to expand these studies to thorium alkyl species. We recently reported on the synthesis of a thorium monoalkyl species utilizing a tris-amidinate ancillary framework, specifically $\mathrm{Th}\left(\mathrm{CH}_{2} \mathrm{SiMe}_{3}\right)(\mathrm{BIMA})_{3}$ (where BIMA $\left.=\operatorname{MeC}\left(\mathrm{N}^{\mathrm{i}} \mathrm{Pr}\right)_{2}\right)(\mathbf{1})$, and its ability to insert chalcogen atoms to generate rare thorium chalcogenolate complexes. ${ }^{35}$ In addition to the chalcogen insertion reactivity, the increased electrophilicity of the metal center with respect to analogous Cp-based systems led to the rare $\mathrm{C}-\mathrm{H}$ activation of trimethylamine $\mathrm{N}$-oxide. Inspired by this result, we sought to investigate how the unique properties of this system would impact the reactivity of $\mathbf{1}$ with a variety of small molecules. Here we report on the reactivity of 1 with organic azides, isocyanide, CO, nitrile, 9-BBN, and various protic substrates, as well as the stability of $\mathbf{1}$ under photolytic conditions.
${ }^{a}$ Department of Chemistry, University of California, Berkeley, California 94720, USA. E-mail: arnold@berkeley.edu

${ }^{b}$ Chemical Sciences Division, Lawrence Berkeley National Laboratory, Berkeley, California, 94720, USA

$\dagger$ Electronic supplementary information (ESI) available: Experimental details, NMR spectra, and X-ray crystallographic tables. CCDC 1811106-1811116. For ESI and crystallographic data in CIF or other electronic format see DOI: $10.1039 / \mathrm{c} 7 \mathrm{sc} 05328 \mathrm{~b}$ 


\section{Results and discussion}

Having previously established the ability of $\mathbf{1}$ to undergo chalcogen atom insertion and generate unique thorium chalcogenolates, ${ }^{35}$ we next sought to examine potential insertion chemistry of this monoalkyl system with various small molecules. Evans has described the insertion of carbodiimides and organic azides into one alkyl moiety of $\mathrm{Cp}_{2}^{*} \mathrm{ThMe}_{2} \cdot{ }^{16}$ With this in mind, we targeted the synthesis of a tetrakis(amidinate) complex through the reaction of 1 with $N, N^{\prime}$-diisopropylcarbodiimide (Scheme 1). However, despite forcing conditions (100 ${ }^{\circ} \mathrm{C}$ ), carbodiimide insertion into the Th-C bond was not observed, most likely a result of steric saturation around the metal center. Regardless, the alternative salt metathesis route using one equiv. of $\mathrm{ThCl}_{4}(\mathrm{DME})_{2}$ (ref. 36) and 4.05 equiv. of Li(BIMA)(THF $)^{37}$ and heating to $90{ }^{\circ} \mathrm{C}$ for $5 \mathrm{~d}$ afforded the desired homoleptic complex Th(BIMA) ${ }_{4}$ (2) as colourless crystals in $66 \%$ yield (Scheme 1 ). The ${ }^{1} \mathrm{H}$ NMR spectrum of 2 reflects averaged $C_{4}$-symmetry in solution, with one set of peaks observed for the equivalent amidinate ligands. The molecular structure of 2 , determined by single-crystal X-ray diffraction studies, shows a pseudo-tetrahedral geometry of the amidinate ligands around the thorium center (Fig. 1). The Th- $\mathrm{N}_{\text {amid }}$ bond lengths vary between 2.49 and $2.62 \AA$, a noticeably larger range than that seen in 1 (2.49-2.54 $\AA$ ), indicating the significant steric congestion imposed by the isopropyl groups of the amidinate ligands. The structural parameters of 2 combined with the reaction conditions necessary to form 2 support the notion that insertion of carbodiimide into the Th-C bond was hindered by steric crowding, and indicate that related insertion reactions might be subject to this constraint. Due to the steric protection afforded by the tetrakis(amidinate) framework, and inspired by the work of Evans regarding low-valent thorium chemistry, ${ }^{38}$ we attempted the reduction of 2 with $\mathrm{KC}_{8}$ in the presence of 18-crown-6; nevertheless, no colour change was observed and only starting material was isolated.

Reaction of 1 with an equivalent of $p$-tolyl azide resulted in insertion to form the triazenido complex $\mathrm{Th}[(p$-tolyl $)$
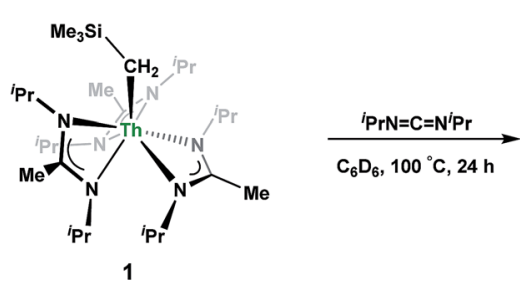

No Reaction

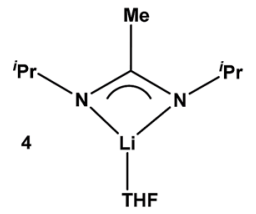

Li(BIMA)(THF)

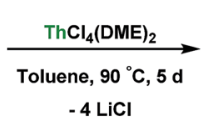

$-4 \mathrm{LiCl}$

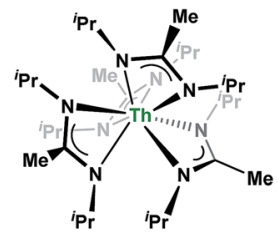

Scheme 1 Attempted insertion and salt metathesis routes to tetrakis(amidinate) species.

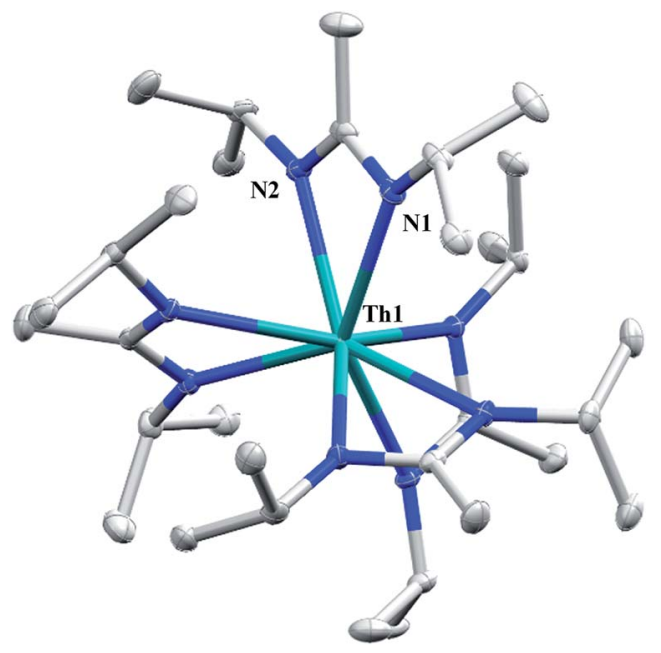

Fig. 1 Molecular structure of 2 (thermal ellipsoids drawn at the 50\% probability level). Hydrogen atoms omitted for clarity.

$\left.\mathrm{NNN}\left(\mathrm{CH}_{2} \mathrm{SiMe}_{3}\right)-\kappa^{2} \mathrm{~N}^{1,2}\right](\mathrm{BIMA})_{3}$ (3) in $83 \%$ yield (Scheme 2). The ${ }^{1} \mathrm{H}$ NMR spectrum displayed the diagnostic downfield shift of the methylene resonance which was also observed to result from chalcogen insertion. ${ }^{35}$ In the present case, we observed a shift from $\delta-0.08$ in 1 to $\delta 3.99$ in 3, alongside shifted amidinate resonances and the appearance of resonances attributable to the $p$-tolyl group. X-ray diffraction studies revealed a $\kappa^{2} \mathrm{~N}^{1,2}$ coordination mode of the triazenido moiety (Fig. 2), similar to that observed by Evans in the thorium metallocene system. ${ }^{16}$ The metrical parameters relating to the $\mathrm{N}_{3}$ fragment show the effect of delocalization, with bond lengths of 1.314(6) and 1.285(6) $\AA$ for $\mathrm{N}(7)-\mathrm{N}(8)$ and $\mathrm{N}(8)-\mathrm{N}(9)$, respectively, a difference of only $\sim 0.03 \AA$. In contrast, Evans' system that utilized adamantyl azide exhibited a more localized bonding for the analogous nitrogens, with bond lengths of 1.360(3) and 1.243(3) A, a difference of $\sim 0.12 \AA .^{16}$ The Th(1)-N(7) distance of $2.474(4) \AA$ is $\sim 0.1 \AA$ longer than that seen in the thorium metallocene system, while the $\operatorname{Th}(1)-\mathrm{N}(8)$ distance of $2.597(4) \AA$ is
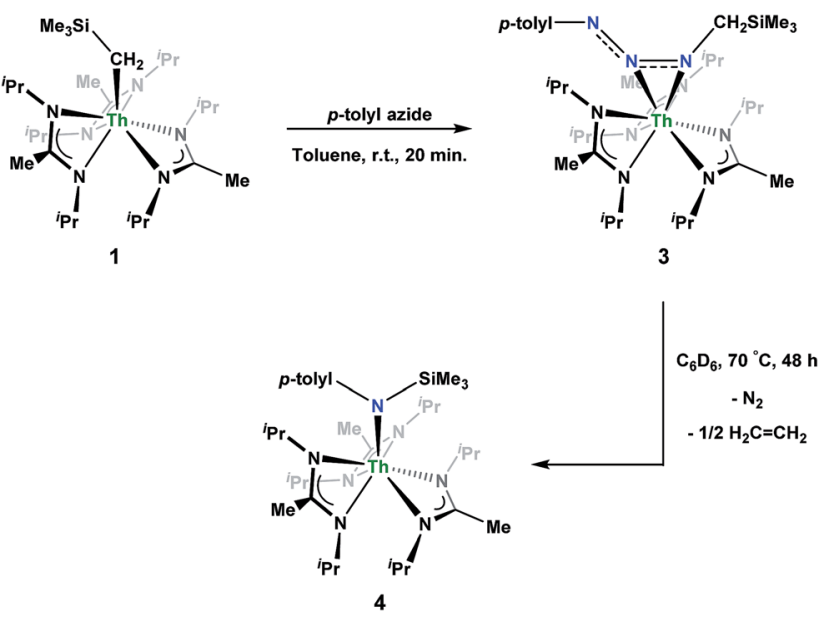

Scheme 2 Synthesis of 3 and thermal decomposition to 4 . 


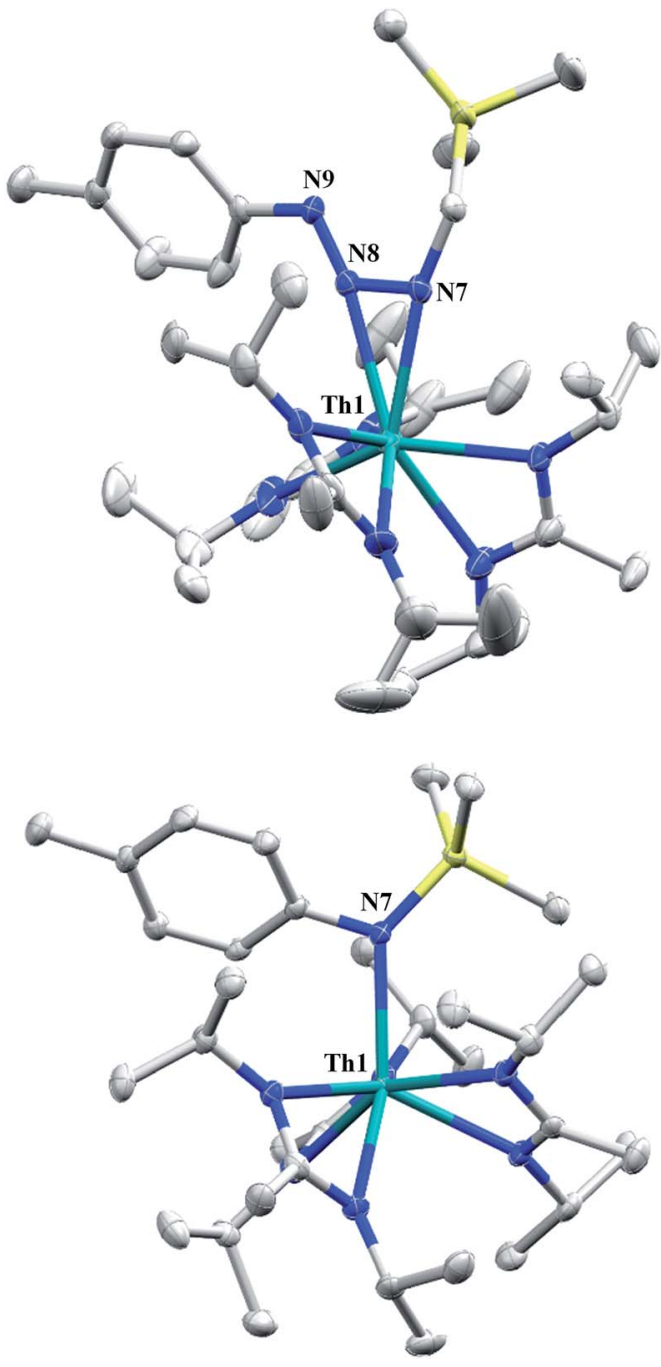

Fig. 2 Molecular structures of 3 (top) and 4 (bottom) (thermal ellipsoids drawn at the $50 \%$ probability level). Hydrogen atoms omitted for clarity.

the same in both. This indicates that the Th(1)-N(7) interaction is best described as anionic, whereas $\mathrm{Th}(1)-\mathrm{N}(8)$ is more dative. The difference between 3 and Evans' metallocene system is likely a combination of both steric and electronic effects. Insertion with tert-butyl azide was also achieved; however, a mixture of two species was always observed, with the major product slowly converting to the minor product in solution until a ratio of $\sim 4: 1$ was established. Heating did not alter this ratio, although elevated temperatures $\left(100{ }^{\circ} \mathrm{C}\right)$ induced decomposition of the products. We postulate that the two products are both triazenido complexes that differ only in their coordination mode, with the $\kappa^{2} \mathrm{~N}^{1,2}$ and $\kappa^{2} \mathrm{~N}^{1,3}$ species present in solution. Exposing 3 to elevated temperatures in solution to see if a similar change in coordination mode would occur brought about a different result; 3 undergoes clean thermal decomposition to a new complex, with significantly shifted $p$-tolyl aromatic resonances and, most notably, no methylene resonance. Complete conversion was achieved within $48 \mathrm{~h}$ while heating at $70{ }^{\circ} \mathrm{C}$. This new product was stable to further heating.
Close inspection of the ${ }^{1} \mathrm{H}$ NMR spectrum revealed a resonance attributable to ethylene. With this information we envisioned that 3 was losing diazomethane $\left(\mathrm{N}_{2} \mathrm{CH}_{2}\right)$, which then decomposed to dinitrogen and ethylene, ${ }^{39}$ resulting in the thorium amido species $\mathrm{Th}\left[(p\right.$-tolyl $\left.) \mathrm{N}\left(\mathrm{SiMe}_{3}\right)\right](\mathrm{BIMA})_{3}$ (4, Scheme 2). Ethylene formation may be the result of singlet methylene ${ }^{\mathbf{4 0}}$ generation and coupling upon $\mathrm{N}_{2} \mathrm{CH}_{2}$ decomposition. In order to try and trap the transient singlet methylene, similar heating experiments were conducted in the presence of 2-butyne and 1,1-diphenylethylene and monitored by ${ }^{1} \mathrm{H}$ NMR spectroscopy. Although it was difficult to unambiguously identify the trapped products (1,2-dimethylcyclopropene and 1,1-diphenylcyclopropane, respectively), the formation of ethylene was not seen with either trapping reagent, and a singlet at $\delta 1.13$ was observed in the 1,1-diphenylethylene experiment, which we tentatively assign to 1,1-diphenylcyclopropane. ${ }^{\mathbf{1 1}}$ We were able to confirm the identity of $\mathbf{4}$ as the thorium amido complex by X-ray diffraction studies (Fig. 2). To the best of our knowledge, this is the first example of clean thermal decomposition of an actinide triazenido complex to the corresponding amido species. Bart and co-workers have observed thermal instability in certain uranium triazenido species, which has led to intractable mixtures of products. ${ }^{42}$ However, the thermal decomposition of $\mathrm{L}^{t \mathrm{Bu}} \mathrm{Fe}\left(\eta^{2}\right.$-HNNNAd) (where $\mathrm{L}^{t \mathrm{Bu}}=$ tert-butyl substituted- $N, N^{\prime}$ diaryl- $\beta$-diketiminate, aryl $=2,6-{ }^{\mathrm{i}} \mathrm{Pr}_{2}-\mathrm{C}_{6} \mathrm{H}_{3}$ ) to the corresponding primary amido species $\mathrm{L}^{t \mathrm{Bu}} \mathrm{FeNHAd}$ has been observed. ${ }^{43}$ This was rationalized based on the instability of free $\mathrm{H}_{2} \mathrm{NNNR}$ compounds with respect to loss of dinitrogen. The $\operatorname{Th}(1)-\mathrm{N}(7)$ bond distance of 2.399(2) $\AA$ in 4 is very close to the Th-N bond distance of 2.389(2) A observed by Walter and co-workers in $\left[\eta^{5}\right.$ 1,2,4-( $\left.\left(\mathrm{Me}_{3} \mathrm{C}\right)_{3} \mathrm{C}_{5} \mathrm{H}_{2}\right]_{2} \mathrm{Th}(\mathrm{Cl})-\left[\mathrm{N}(p\right.$-tolyl $\left.) \mathrm{SiH}_{2} \mathrm{Ph}\right]$, which has a similar silyl amide environment. ${ }^{44}$ The nitrogen atom of the amido exhibits a trigonal planar geometry $\left(\Sigma \angle \approx 360^{\circ}\right)$, also consistent with Walter's complex. A series of NMR scale experiments revealed the thermal decomposition to be concentration dependent, with higher concentrations of 3 leading to the generation of the silyl amine ( $p$-tolyl) $\mathrm{NH}\left(\mathrm{SiMe}_{3}\right)$ (as determined by ${ }^{1} \mathrm{H}$ NMR spectroscopy) and a mixture of unknown species (see Fig. S7 in ESI $\dagger$ ). The identity of these products, along with mechanistic studies regarding the formation of $\mathbf{4}$ from $\mathbf{3}$, is currently under investigation.

Although achieved with both transition metal ${ }^{45-48}$ and uranium $^{49-52}$ species, isocyanide insertion into thorium alkyl bonds to form the corresponding $\eta^{2}$-iminoacyl complexes has not yet been reported. While sterics precluded the insertion of $N, N^{\prime}$-diisopropylcarbodiimide, isocyanide insertion was realized with one equivalent of 2,6-dimethylphenylisocyanide and moderate heating, resulting in $\mathrm{Th}\left[\eta^{2}-(\mathrm{C}=\mathrm{N})-2,6-\mathrm{Me}_{2}-\mathrm{C}_{6} \mathrm{H}_{3}\right.$ $\left.\left(\mathrm{CH}_{2} \mathrm{SiMe}_{3}\right)\right](\mathrm{BIMA})_{3}(5)$ as a colourless, crystalline solid in $81 \%$ yield (Scheme 3). To the best of our knowledge this is the first thorium $\eta^{2}$-iminoacyl complex. Monitoring the reaction by ${ }^{1} \mathrm{H}$ NMR spectroscopy confirms that this insertion proceeds slowly at room temperature ( $>95 \%$ conversion after $96 \mathrm{~h}$ ), presumably due to the steric clash between the xylyl moiety and amidinate ligands. As expected, the diagnostic downfield shift of the methylene singlet to $\delta 2.85$ indicated successful isocyanide insertion, along with new methyl and aromatic resonances 


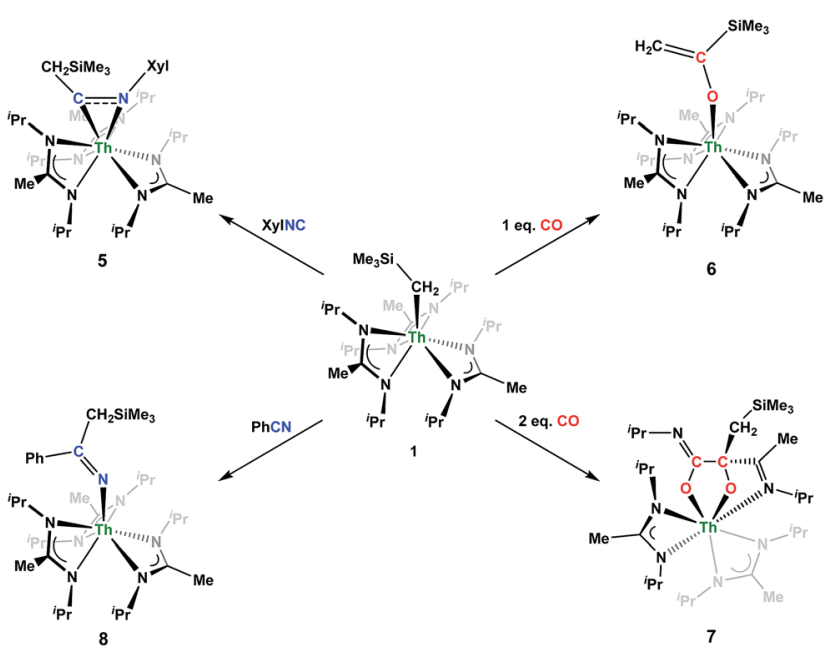

Scheme 3 Insertion reactivity of 1.

corresponding to the xylyl group. X-ray diffraction studies revealed the $\eta^{2}$-coordination mode of the imine moiety, with the $\mathrm{N}(7)-\mathrm{C}(29)$ bond length of 1.299(4) $\AA$ falling in the range seen for other transition metal iminoacyl species (Fig. 3). ${ }^{45-52}$ The $\mathrm{Th}(1)-\mathrm{N}(7)$ distance of 2.469(2) $\AA$ is noticeably shorter than that typically observed for a dative Th-N bond, ${ }^{53-56}$ while the $\mathrm{Th}(1)-\mathrm{C}(29)$ bond length of $2.529(3) \AA$ is in the range observed for other $\sigma$-bonded alkyl moieties. ${ }^{14,19,57}$ This insertion differs from that observed by Andersen and co-workers in their $\mathrm{Th}\left(\mathrm{CH}_{2} \mathrm{SiMe}_{2} \mathrm{NSiMe}_{3}\right)\left(\mathrm{NR}_{2}\right)_{2}$ (where $\left.\mathrm{R}=\mathrm{SiMe}_{3}\right)$ complex, which undergoes insertion of tert-butyl isocyanide into the $\mathrm{C}-\mathrm{Si}$ bond of the metallacycle to produce $\mathrm{Th}\left[\left({ }^{ } \mathrm{Bu}\right) \mathrm{NC}\left(\mathrm{CH}_{2}\right) \mathrm{SiMe}_{2} \mathrm{NSiMe}_{3}\right]$ $\left(\mathrm{NR}_{2}\right)_{2} \cdot{ }^{58}$ Similar reactivity was observed with $\mathrm{CO}$ in Andersen's system, resulting in $\mathrm{Th}\left[\left(\mathrm{OC}\left(=\mathrm{CH}_{2}\right) \mathrm{SiMe}_{2} \mathrm{NSiMe}_{3}\right)\right]$ $\left(\mathrm{NR}_{2}\right)_{2}$. Exposing 1 to $1 \mathrm{~atm}$ of $\mathrm{CO}$ resulted in the formation of two products with similar solubilities in non-polar solvents,

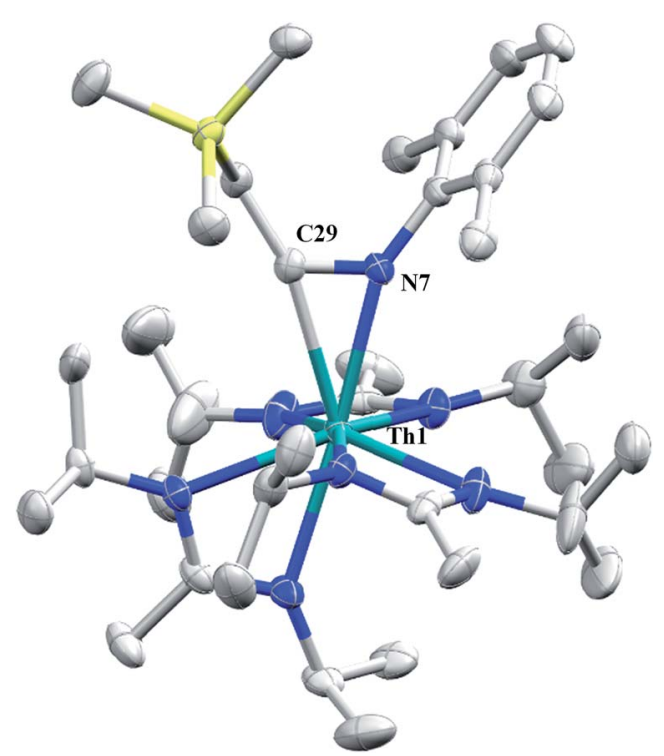

Fig. 3 Molecular structure of 5 (thermal ellipsoids drawn at the 50\% probability level). Hydrogen atoms omitted for clarity. precluding their clean isolation and characterization, despite yields of $\sim 80 \%$ for the bulk mixture. The major species, as identified by ${ }^{1} \mathrm{H}$ NMR spectroscopy, exhibited inequivalent methylene protons that are consistent with those observed in $\operatorname{Th}\left[\left(\mathrm{OC}\left(=\mathrm{CH}_{2}\right) \mathrm{SiMe}_{2} \mathrm{NSiMe}_{3}\right)\right]\left(\mathrm{NR}_{2}\right)_{2}$ (see Fig. S10 in ESI $\dagger$ ). This inequivalency would not be seen in the ${ }^{1} \mathrm{H}$ NMR spectrum of the thorium acyl species generated by simple $\mathrm{CO}$ insertion into the Th-C bond; thus, we postulated that it was likely a similar insertion into the $\mathrm{C}-\mathrm{Si}$ bond of $\mathbf{1}$ occurred (Scheme 3). This hypothesis was proven by X-ray diffraction studies, as a few Xray quality crystals were isolated from a very concentrated pentane solution stored at $-35{ }^{\circ} \mathrm{C}$ for 3 days, confirming the identity of the CO insertion as the enolate complex $\operatorname{Th}[\mathrm{OC}(=$ $\left.\left.\mathrm{CH}_{2}\right) \mathrm{SiMe}_{3}\right](\mathrm{BIMA})_{3}(\mathbf{6})$ (Fig. 4). Complex 6 crystallized with two independent molecules in the asymmetric unit due to disorder in the enolate moiety; thus, the metrical parameters of only the nondisordered molecule will be discussed. The Th(1)-O(1) bond

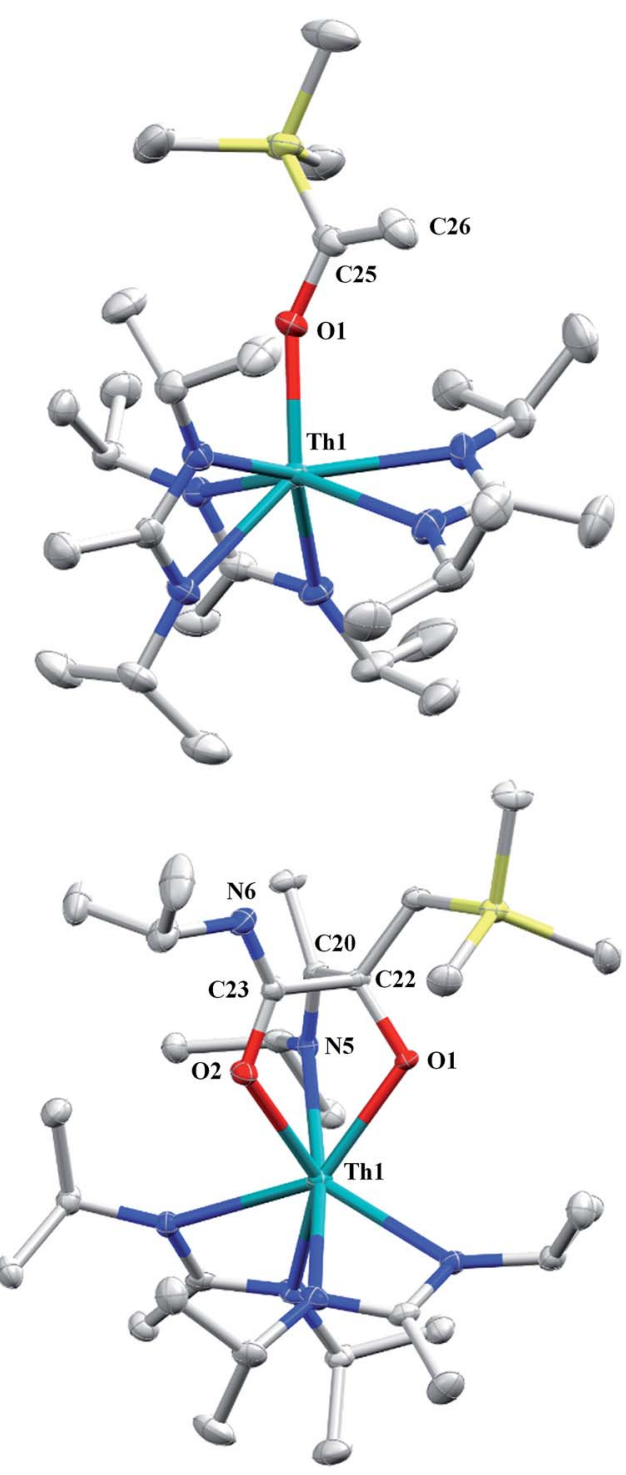

Fig. 4 Molecular structures of 6 (top) and 7 (bottom) (thermal ellipsoids drawn at the $50 \%$ probability level). Hydrogen atoms omitted for clarity. 
length of 2.216(2) $\AA$ is slightly longer than the Th-O bond length of 2.166(2) ̊ seen in $\mathrm{Th}\left(\mathrm{OCH}_{2} \mathrm{NMe}_{2}\right)(\mathrm{BIMA})_{3},{ }^{35}$ while the $\mathrm{C}(25)-$ $\mathrm{C}(26)$ bond length of $1.338(5) \AA$ is consistent with a carboncarbon double bond, and the trigonal planar geometry of C25 $\left(\Sigma \angle \approx 360^{\circ}\right)$ indicates $\mathrm{sp}^{2}$ hybridization. This type of reactivity has precedent in both uranium and thorium systems, ${ }^{52,58-61}$ and has been explained by initial $\mathrm{CO}$ insertion into the $\mathrm{M}-\mathrm{C}$ bond to form the metal acyl, which then isomerizes to form a carbenelike intermediate that can then insert into the $\mathrm{Si}-\mathrm{C}$ bond (Scheme 4). Alongside crystals of 6 were crystals of a different product, which we have tentatively assigned to the other resonances observed in the ${ }^{1} \mathrm{H}$ NMR spectrum of the bulk material (see Fig. S10 in ESI $†$ ). X-ray diffraction studies revealed this product to be $\mathrm{Th}\left[\mathrm{OC}\left(\mathrm{N}^{\mathrm{i}} \mathrm{Pr}\right) \mathrm{C}\left(\mathrm{CH}_{2} \mathrm{SiMe}_{3}\right)\left(\mathrm{C}(\mathrm{Me}) \mathrm{N}\left({ }^{\mathrm{i}} \mathrm{Pr}\right)\right) \mathrm{O}\right.$ $\left.\kappa^{2} \mathrm{O}, \mathrm{O}^{\prime}\right](\mathrm{BIMA})_{2}(7)$, the result of reductive CO coupling and insertion into an amidinate ligand (Fig. 4). The Th(1)-O(1) and $\mathrm{Th}(1)-\mathrm{O}(2)$ bond lengths of 2.220(2) and 2.290(2) $\AA$, respectively, are slightly longer than that seen in 6 and $\mathrm{Th}\left(\mathrm{OCH}_{2} \mathrm{NMe}_{2}\right)^{-}$ (BIMA) $)_{3},{ }^{35}$ while the bond length of 2.764(3) $\AA$ for $\mathrm{Th}(1)-\mathrm{N}(5)$ is indicative of a dative interaction..$^{53-56} \mathrm{~A}$ single bond length of $1.558(5) \AA$ is observed for $\mathrm{C}(22)-\mathrm{C}(23)$, whereas imine bonds are seen for $\mathrm{C}(23)-\mathrm{N}(6)$ and $\mathrm{C}(20)-\mathrm{N}(5)(1.266(4)$ and 1.282(4) $\AA$, respectively). This type of $\mathrm{CO}$ coupling mimics the enediolate formation observed with various actinide bis-alkyl systems. ${ }^{59,62}$ Regarding the formation of 7 , it seems unlikely that this product is obtained from the interaction of a molecule of $\mathrm{CO}$ with $\mathbf{6}$, due to the intact nature of the trimethylsilylmethyl alkyl fragment. Instead, it is likely that 7 results from "trapping" of the carbene-like intermediate, which precedes formation of $\mathbf{6}$, by another molecule of $\mathrm{CO}$ to form a transient ketene, ${ }^{63}$ and subsequent insertion and rearrangement steps lead to 7 as the final product (Scheme 4). Kinetically this intermolecular

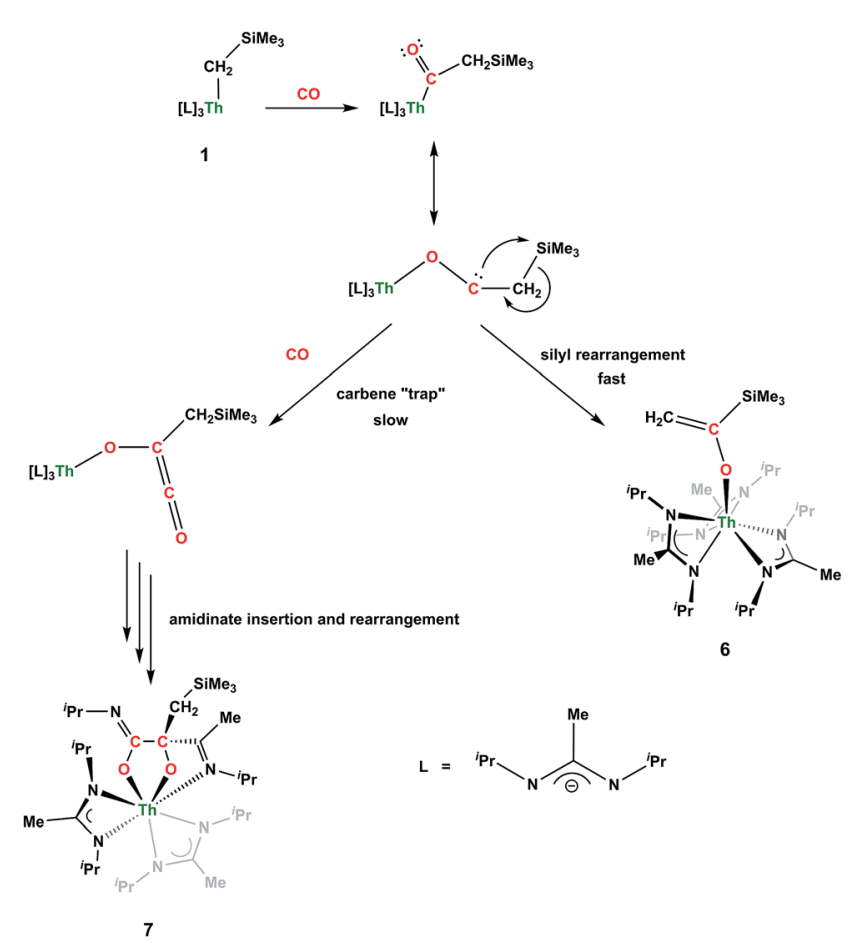

Scheme 4 Proposed pathways for the formation of 6 and 7. process is slower than the intramolecular attack by the carbene intermediate on the $\mathrm{C}-\mathrm{Si}$ bond, producing 6 as the major product. Exposing a mixture of $\mathbf{6}$ and 7 to additional CO did not change the ratio of products observed, confirming that 7 is not generated from 6. In an attempt to avoid the formation of 7 , the slow addition of 1 eq. of $\mathrm{CO}$ to a stirred hexanes solution of $\mathbf{1}$ was conducted, resulting in clean formation of 6 in $64 \%$ yield. Development of a synthetic strategy to produce 7 is currently underway. Looking to other small molecules, insertion reactivity with $\mathrm{CO}_{2}$ and $\mathrm{CS}_{2}$ did not proceed cleanly, yielding intractable mixtures.

Nitrile insertion was examined by the NMR-scale reaction of 1 and benzonitrile. The reaction was sufficiently complete (>95\% conversion by ${ }^{1} \mathrm{H}$ NMR spectroscopy) upon heating to $100{ }^{\circ} \mathrm{C}$ for $72 \mathrm{~h}$, resulting in the ketimide complex $\mathrm{Th}[-\mathrm{N}=$ $\left.\mathrm{C}(\mathrm{Ph})\left(\mathrm{CH}_{2} \mathrm{SiMe}_{3}\right)\right](\mathrm{BIMA})_{3}$ (8) (Scheme 3). The methylene singlet is seen downfield at $\delta 2.73$, along with new resonances corresponding to the aromatic protons of the phenyl ring, as well as aromatic resonances corresponding to the cyclotrimerization product of benzonitrile, 2,4,6-triphenyl-1,3,5-triazine (see Fig. S13 in ESI $\dagger$ ) ${ }^{64}$ The Lewis acid-catalysed cyclotrimerization of benzonitrile has been previously reported for lanthanideimido species, ${ }^{64}$ although the active species in this transformation has not been identified.

Looking to exploit the basic nature of the alkyl moiety of $\mathbf{1}$, protonolysis reactivity was explored with a variety of protic substrates, the results of which are summarized in Scheme 5 . NMR-scale experiments were carried out with 1 and 2,6-diisopropylaniline, resulting in the primary amido species $\mathrm{Th}\left(\mathrm{NH}^{-}\right.$ 2,6- $\left.{ }^{\mathrm{i}} \mathrm{Pr}_{2}-\mathrm{C}_{6} \mathrm{H}_{3}\right)(\mathrm{BIMA})_{3}(\mathbf{9})$, as well as $\mathbf{1}$ and 2,6-di-tert-butylphenol, resulting in the aryloxide complex $\mathrm{Th}\left(\mathrm{O}-2,6-{ }^{t} \mathrm{Bu}_{2}-\mathrm{C}_{6} \mathrm{H}_{3}\right)$ (BIMA) ${ }_{3}(\mathbf{1 0})$, as determined by ${ }^{1} \mathrm{H}$ NMR spectroscopy. While phenol addition and subsequent elimination of $\mathrm{SiMe}_{4}$ occurred within $12 \mathrm{~h}$ at room temperature, deprotonation of the aniline required extended reaction times at elevated temperatures before conversion to 9 was achieved. This can be rationalized on the basis of the higher $\mathrm{p} K_{\mathrm{a}}$ of the aniline ( $\sim 30$ vs. 16.8 in

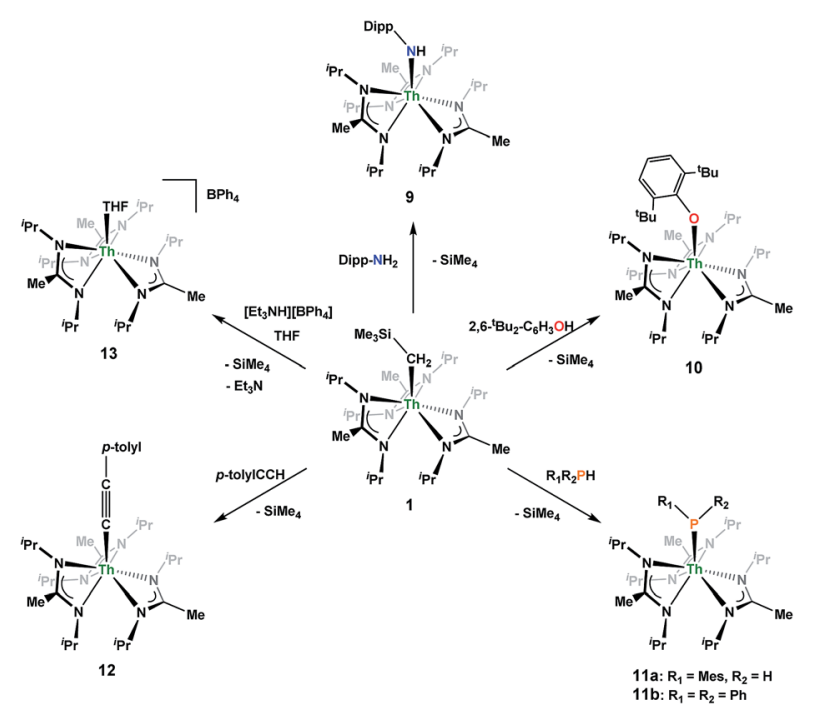

Scheme 5 Protonolysis reactivity of 1 . 
DMSO), ${ }^{65,66}$ as the sterics imposed by the 2,6-di-tert-butylphenol are greater than that of 2,6-diisopropylaniline.

Similar NMR experiments were also performed with primary and secondary phosphines, namely mesitylphosphine and diphenylphosphine, resulting in the thorium phosphido complexes Th(PHMes)(BIMA) ${ }_{3}$ (11a) (Mes = 2,4,6-trimethylphenyl) and $\mathrm{Th}\left(\mathrm{PPh}_{2}\right)(\mathrm{BIMA})_{3}(\mathbf{1 1 b})$, respectively, as determined by ${ }^{1} \mathrm{H}$ and ${ }^{31} \mathrm{P}$ NMR spectroscopy. Complex 11a exhibits a doublet at $\delta-45.4$ in the ${ }^{31} \mathrm{P}$ NMR spectrum with a ${ }^{1} J_{\mathrm{P}, \mathrm{H}}$ coupling constant of $195 \mathrm{~Hz}$; the corresponding doublet in the ${ }^{1} \mathrm{H}$ NMR is observed at $\delta 3.41$. In the ${ }^{31} \mathrm{P}$ NMR spectrum of $\mathbf{1 1 b}$ a singlet is observed at $\delta 89.5$ corresponding to the thorium phosphido, alongside peaks consistent with the dehydrocoupled product $\mathrm{Ph}_{2} \mathrm{P}-\mathrm{PPh}_{2}(\delta-14.9)^{67}$ and an unidentified phosphorus-containing species $\left(\delta\right.$ 106). These ${ }^{31} \mathrm{P}$ chemical shifts are in the range reported for other primary and secondary thorium phosphido species. ${ }^{68-70}$ The dehydrocoupling of phosphines has been reported with zirconium phosphido complexes under similar reaction conditions. ${ }^{71}$ Both complexes 11a and 11b required elevated temperatures and prolonged reaction times to reach completion. We sought a more scalable strategy to synthesize 11a without the need for harsh reaction conditions, as complex 11a has the potential to form a thorium phosphinidene via deprotonation of the phosphide ligand. With few examples of thorium phosphinidenes available, this would provide valuable information regarding metal-ligand multiple bonding between thorium and the heavier pnictogens. ${ }^{72-74}$ Salt metathesis between the previously reported ThCl(BIMA) ${ }_{3}$ (ref. 35) and $\mathrm{KPHMes}^{\mathbf{7 0}}$ provided a more direct route to 11 a as bright yellow crystals in $58 \%$ yield. The ${ }^{13} \mathrm{C}\left\{{ }^{1} \mathrm{H}\right\}$ NMR spectrum of 11a exhibits rare through-space coupling of the phosphorus atom and the isopropyl methyl carbons of the BIMA ligand ( ${ }^{\mathrm{TS}} J_{\mathrm{P}, \mathrm{C}}=2.1 \mathrm{~Hz}$ ), as well as the ortho-methyls of the mesitylene ring $\left({ }^{\mathrm{TS}} J_{\mathrm{P}, \mathrm{C}}=9.6 \mathrm{~Hz}\right) \cdot{ }^{75-78}$ This coupling is supported by the X-ray crystal structure of 11a, which displays a close proximity of the phosphorus atom to one of the BIMA isopropyl methyls (3.746(4) and 3.779(4) ̊) and mesityl methyls (3.062(3) and $3.070(3) \AA$ ), along with significant pyramidalization at $\mathrm{P}$ $\left(\Sigma \angle \approx 311^{\circ}\right)$ in the two independent molecules found in the asymmetric unit (Fig. 5). The orientation of the phosphorus lone pair toward these carbon atoms facilitates this spin-spin interaction. This is the first crystallographically characterized example of a thorium monophosphido species bearing a primary phosphide ligand; to date, only a handful of primary bis(phosphido)-thorium species have been isolated and characterized. ${ }^{70,72,79}$ The Th-P bond lengths seen in the two molecules in the asymmetric unit (3.0497(8) and 3.0404(8) A) are $\sim 0.15 \AA$ longer than those observed in the previously reported bis(phosphido)-thorium complexes. Attempts to deprotonate 11a to form the corresponding thorium phosphinidene have thus far proven unsuccessful.

The reaction of $\mathbf{1}$ with $p$-tolylacetylene proceeds cleanly, providing the thorium acetylide complex $\mathrm{Th}(\mathrm{C} \equiv \mathrm{C}-p$ tolyl)(BIMA) $)_{3}$ (12) as colourless crystals in 95\% yield. This new alkynyl species may serve as a useful starting material for future chemistry, as other thorium acetylide complexes have been shown to be active catalysts for the linear oligomerization of

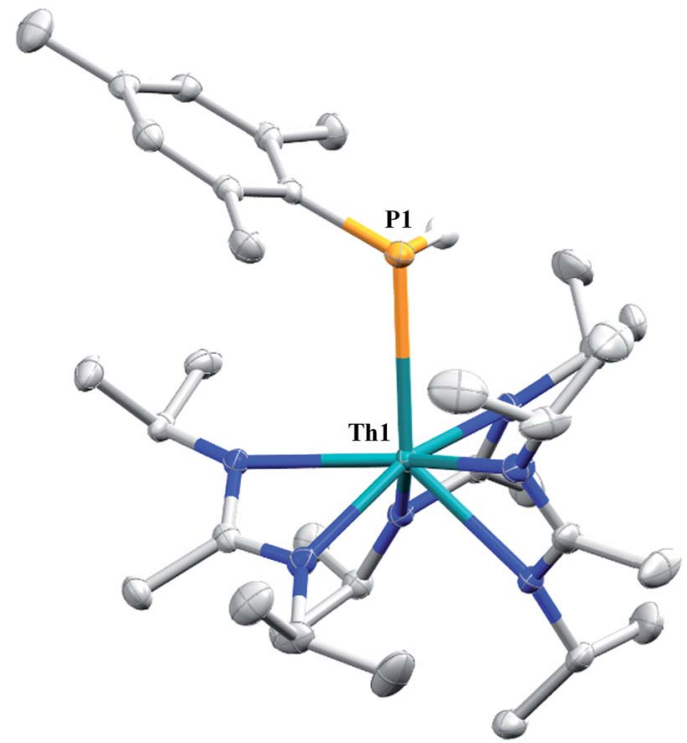

Fig. 5 Molecular structure of 11a (thermal ellipsoids drawn at the 50\% probability level). Non-phosphorus-bound hydrogen atoms omitted for clarity.

terminal alkynes. ${ }^{80}$ The ${ }^{1} \mathrm{H}$ NMR spectrum displays a $C_{3^{-}}$ symmetric amidinate environment along with resonances attributable to the $p$-tolyl group, while the ${ }^{13} \mathrm{C}\left\{{ }^{1} \mathrm{H}\right\}$ NMR spectrum features a downfield resonance of $\delta 189.2$ corresponding to the thorium-bound carbon atom of the alkyne, consistent with other thorium and group IV acetylides. ${ }^{\mathbf{8 1 - 8 4}}$ The IR spectrum exhibits a characteristic signal at $2061 \mathrm{~cm}^{-1}$ assigned to the $\mathrm{C} \equiv \mathrm{C}$ stretch. X-ray diffraction studies revealed a near-linear $\mathrm{Th}-\mathrm{C} \equiv \mathrm{C}$ bond angle of $175.7(2)^{\circ}$ and bond lengths of 2.542(2) and $1.219(3) \AA$ for $\mathrm{Th}(1)-\mathrm{C}(25)$ and $\mathrm{C}(25)-\mathrm{C}(26)$, respectively (Fig. 6). The Th-C bond length in 12 is $\sim 0.05 \AA$ longer than that of the few other thorium acetylide species to have been characterized crystallographically, namely $\left[(\mathrm{L}) \mathrm{Th}\left(\mathrm{C} \equiv \mathrm{CSiMe}_{3}\right)_{2}\right]$ and $\left[(\mathrm{L}) \mathrm{Th}\left(\mathrm{C} \equiv \mathrm{CSi}^{\mathrm{i}} \mathrm{Pr}_{3}\right)_{2}\right]$ (where $\mathrm{L}=$ trans-calix[2]benzene[2]pyrrolide), and $\mathrm{Th}\left(\mathrm{Bc}^{\mathrm{Mes}}\right)_{2}(\mathrm{C} \equiv \mathrm{C}-p \text {-tolyl })_{2}$ (where $\mathrm{Bc}^{\mathrm{Mes}}=$ mesitylsubstituted bis(NHC)borate, NHC $=$ N-heterocyclic carbene), which were only recently reported. ${ }^{27,75}$

A cationic species was targeted as a potential precursor to a Th(III) amidinate complex, as Evans has shown that reduction of a mixed cyclopentadienyl amidinate thorium cation, namely $\left\{\left(\mathrm{C}_{5} \mathrm{Me}_{5}\right)_{2}\left[{ }^{\mathrm{i}} \mathrm{PrNC}(\mathrm{Me}) \mathrm{N}^{\mathrm{i}} \mathrm{Pr}\right] \mathrm{Th}\right\}\left\{\mathrm{BPh}_{3} \mathrm{Me}\right\}$, can be achieved with $\mathrm{KC}_{8}{ }^{85}$ Treatment of 1 with $\left[\mathrm{Et}_{3} \mathrm{NH}\right]\left[\mathrm{BPh}_{4}\right]^{86}$ in THF led to the isolation of $\left[\mathrm{Th}(\mathrm{THF})(\mathrm{BIMA})_{3}\right]\left[\mathrm{BPh}_{4}\right](\mathbf{1 3})$ as colourless crystals in $81 \%$ yield. The $\mathrm{NH}_{3}$ and $\mathrm{SiMe}_{4}$ byproducts were easily removed under vacuum upon workup, and X-ray diffraction studies show a well separated ion pair with one THF molecule coordinated to the thorium center and another co-crystallized in the lattice (Fig. 7). The Th- $\mathrm{N}_{\text {amid }}$ bond lengths are noticeably shorter (2.45$2.48 \AA$ ) than that of 1 or 2 , likely due to reduced steric congestion and higher electrophilicity of the metal center. The Th(1)-O(1) distance of 2.504(2) $\AA$ is in the range observed for other THFbonded thorium complexes. ${ }^{87-90}$ The second equivalent of THF can be removed under high vacuum. The ${ }^{1} \mathrm{H}$ NMR spectrum of dried 13 in $\mathrm{CDCl}_{3}$ displays equivalent amidinate resonances, the 


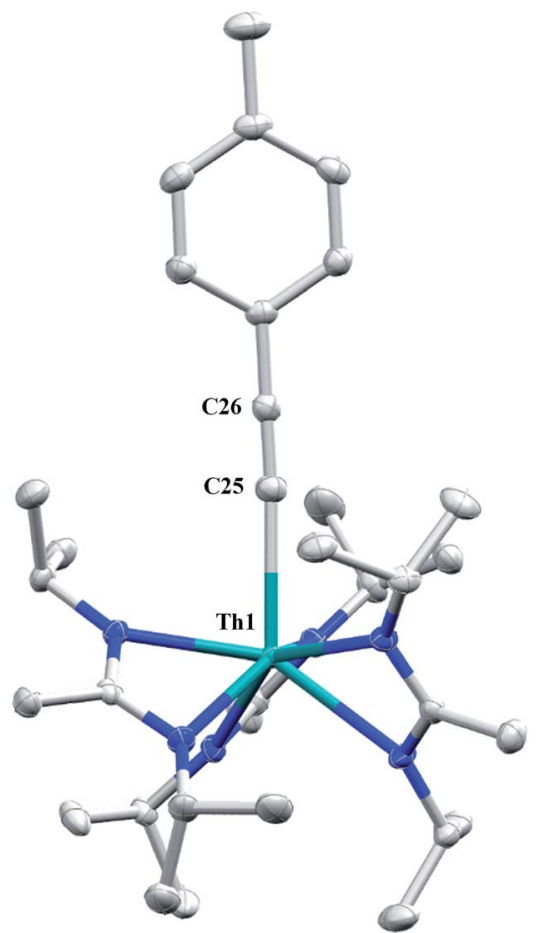

Fig. 6 Molecular structure of 12 (thermal ellipsoids drawn at the 50\% probability level). Hydrogen atoms omitted for clarity.

aromatic peaks of the $\mathrm{BPh}_{4}$ anion, and one set of resonances corresponding to coordinated THF. The complex displays appreciable stability in $\mathrm{CDCl}_{3}$, but begins to decompose after $\sim 24 \mathrm{~h}$ at room temperature. Attempted reduction of 13 with $\mathrm{KC}_{8}$

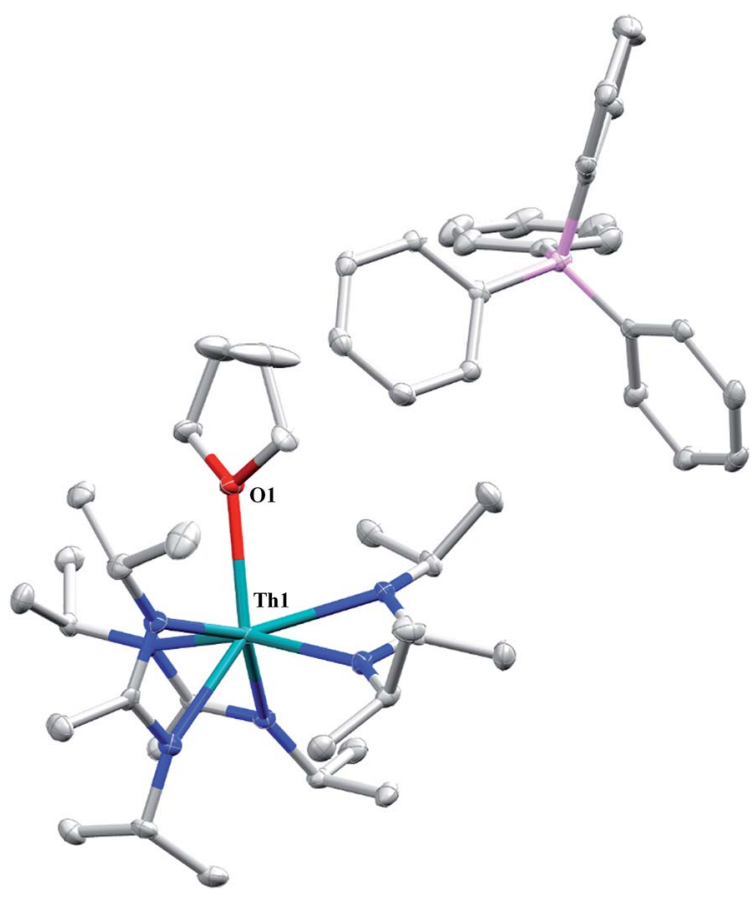

Fig. 7 Molecular structure of 13 (thermal ellipsoids drawn at the 50\% probability (evel). Hydrogen atoms and THF solvent molecule omitted for clarity. in THF led to the isolation of 2 . No colour change was observed throughout the reaction. Increasing the sterics of the $\mathrm{R}$ groups on the amidinate nitrogens may help stabilize a tris-amidinate Th(III) complex, and work is currently ongoing to test this hypothesis. Attempts to utilize $\mathrm{H}_{2}$ as a protic substrate and form a thorium hydride complex were not successful.

Complex 1 undergoes ligand exchange with one equivalent of 9-borabicyclo[3.3.1] nonane (9-BBN), affording (BIMA) ${ }_{3} \mathrm{Th}(\mu$ $\mathrm{H})_{2}\left[\mathrm{~B}\left(\mathrm{C}_{8} \mathrm{H}_{14}\right)\right]$ (14) alongside one equivalent of $\left(\mathrm{C}_{8} \mathrm{H}_{14}\right) \mathrm{B}\left(\mathrm{CH}_{2}-\right.$ $\mathrm{SiMe}_{3}$ ), as determined by ${ }^{11} \mathrm{~B}\left\{{ }^{1} \mathrm{H}\right\}$ NMR spectroscopy (resonance observed at $\delta 84.3$ in $\left.\mathrm{C}_{6} \mathrm{D}_{6}\right) \cdot{ }^{91}$ Complex 14 was isolated in $66 \%$ crystalline yield after workup (Scheme 6). The thorium borohydride complex exhibits equivalent amidinate ligands in solution according to ${ }^{1} \mathrm{H}$ NMR spectroscopy. Additionally, broad $\mu-H$ resonances and several multiplets corresponding to the $\mathrm{C}_{8} \mathrm{H}_{14}$ fragment are observed. The ${ }^{11} \mathrm{~B}\left\{{ }^{1} \mathrm{H}\right\}$ NMR spectrum exhibits a single resonance at $\delta 4.90$, which is in the range typically observed for boron hydrides.92 ${ }^{92}$ FIR spectroscopy reveals a broad $\mathrm{B}-\mathrm{H}$ stretch centered at $2021 \mathrm{~cm}^{-1}$. X-ray diffraction studies show an eight-coordinate thorium center bearing bridging hydrides bound to the 9-BBN moiety (Fig. 8). The hydrides were located in the Fourier difference map and refined isotropically. The $\operatorname{Th}(1)-\mathrm{B}(1)$ distance of $2.952(9) \AA$ is significantly longer than typically observed with other thorium complexes containing bridging borohydrides (2.49(6)-2.670(2) $\AA$ A), ${ }^{93-97}$ but is within the range observed by Girolami and coworkers in the complexes $\left[\mathrm{Th}\left(\mathrm{H}_{3} \mathrm{BNMe}_{2} \mathrm{BH}_{3}\right)_{4}\right]$ and $\left[\mathrm{Th}\left(\mathrm{H}_{3}\right.\right.$ $\left.\left.\mathrm{BNMe}_{2} \mathrm{BH}_{3}\right)_{2}\left(\mathrm{BH}_{4}\right)_{2}\right]$, which exhibit Th-B distances between 2.848(9) to 3.193(5) $\AA{ }^{97}$ Complex 14 is surprisingly stable both under photolytic and elevated temperature conditions, with no decomposition or elimination of $\mathrm{H}_{2}$ observed.

Storage of $\mathbf{1}$ at room temperature under dry nitrogen for several weeks led to slight discolouration of the crystalline solid. While the ${ }^{1} \mathrm{H}$ NMR spectrum of this material showed very little change from that of pure $\mathbf{1}$, we decided to investigate the stability of 1 under photolytic conditions. The UV-Vis spectrum of 1 features an absorption with $\lambda_{\max }=295 \mathrm{~nm}$, likely a ligandbased $\pi-\pi^{*}$ transition (see Fig. S31 in ESI $\dagger$ ). Irradiation of 1 with UV-light centered at $253 \mathrm{~nm}$ in $\mathrm{C}_{6} \mathrm{D}_{6}$ and monitoring by ${ }^{1} \mathrm{H}$ NMR spectroscopy showed elimination of $\mathrm{SiMe}_{4}$ alongside the

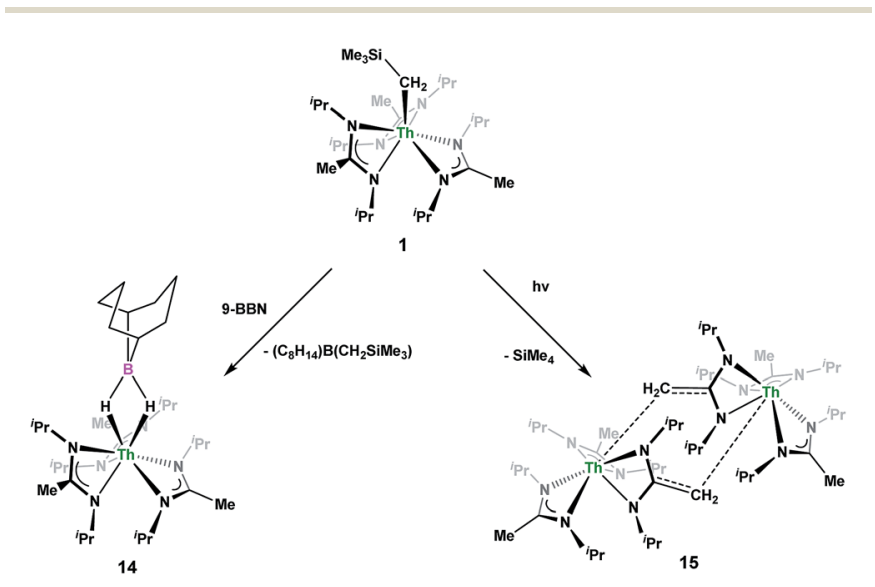

Scheme 6 Ligand exchange and photolytic reactivity of 1. 


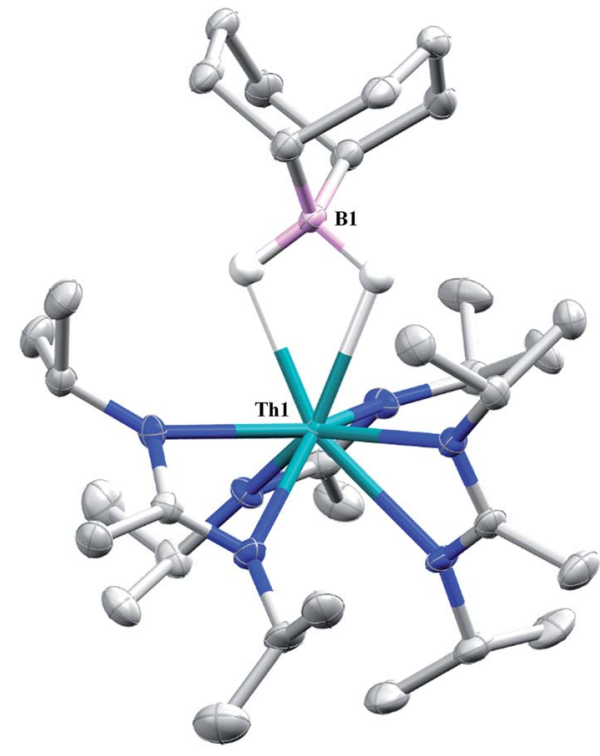

Fig. 8 Molecular structure of 14 (thermal ellipsoids drawn at the 50\% probability (evel). Non-hydride hydrogen atoms omitted for clarity.

production of a single new product, which displayed inequivalent amidinate ligands. Reaction times ranged from $24 \mathrm{~h}$ to 10 days, depending on the concentration of $\mathbf{1}$ in the sample $(\sim 0.02-0.45 \mathrm{M})$, with higher concentrations taking longer. Optimization of the reaction conditions, by use of a quartz reaction vessel, cyclohexane- $\mathrm{d}_{12}$ and a xenon arc lamp, resulted in significantly reduced reaction times $(\sim 2 \mathrm{~h}$ for $\sim 0.03 \mathrm{M}$ solution). Removal of $\mathrm{SiMe}_{4}$ under vacuum and crystallization from toluene afforded Th(BIMA) $)_{2}\left(\right.$ BIMA $\left.^{*}\right)(\mathbf{1 5})$ in $53 \%$ yield $\left[\right.$ BIMA $\left.^{*}=\left({ }^{\mathrm{i}} \mathrm{Pr}\right) \mathrm{NC}\left(\mathrm{CH}_{2}\right) \mathrm{N}\left({ }^{\mathrm{i}} \mathrm{Pr}\right)\right]$. Heating a solution of 1 at $100{ }^{\circ} \mathrm{C}$ for $24 \mathrm{~h}$ and monitoring by ${ }^{1} \mathrm{H}$ NMR spectroscopy showed no decomposition of $\mathbf{1}$ or production of $\mathbf{1 5}$, eliminating the possibility that conversion of $\mathbf{1}$ to $\mathbf{1 5}$ was thermally-induced.

Irradiation of $\mathbf{1}$ results in $\mathrm{C}-\mathrm{H}$ activation of a methyl group on an amidinate ligand by the $-\mathrm{CH}_{2} \mathrm{SiMe}_{3}$ moiety, eliminating $\mathrm{SiMe}_{4}$ and reducing the activated amidinate to a dianionic ligand (Scheme 6). Heterolytic bond cleavage of the Th-C bond resulting in a $-\mathrm{CH}_{2} \mathrm{SiMe}_{3}$ anion, which then attacks the methyl backbone of an amidinate ligand, is a possible explanation for the $\mathrm{C}-\mathrm{H}$ activation and subsequent ligand reduction observed. This is a rare example of an amidinate dianion, ${ }^{64}$ and the first generated under photolytic conditions. The ${ }^{1} \mathrm{H}$ NMR spectrum of $\mathbf{1 5}$ exhibits a set of equivalent amidinate resonances, alongside the resonances attributable to the amidinate dianion, specifically a $2 \mathrm{H}$ septet at $\delta 4.24$, a $2 \mathrm{H}$ singlet at $\delta 3.44$, and a $12 \mathrm{H}$ doublet at $\delta 1.53$. The $6 \mathrm{H}$ singlet corresponding to the methyl groups of the monoanionic amidinates also appears at $\delta 1.53$ (see Fig. S29 in ESI $\uparrow$ ). In the $\left.{ }^{13} \mathrm{C}_{\{1}{ }^{1} \mathrm{H}\right\}$ NMR spectrum the terminal methylene carbon resonance is observed noticeably downfield at $\delta 53.3$, shifted by $\sim 40 \mathrm{ppm}$ from the amidinate methyls seen at $\delta 12.2$, but further upfield than that typically seen with alkenes. The ${ }^{1} J_{\mathrm{C}-\mathrm{H}}$ coupling constant of $157.6 \mathrm{~Hz}$ (as measured from the ${ }^{13} \mathrm{C}$ satellites observed in the ${ }^{1} \mathrm{H}$ NMR spectrum) is consistent with $\mathrm{sp}^{2}$ hybridization and similar to

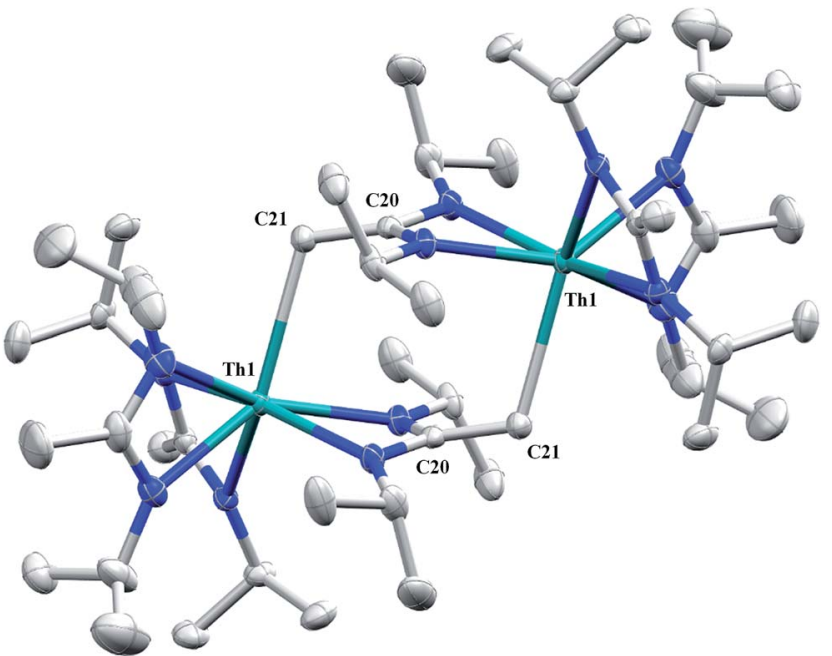

Fig. 9 Molecular structure of 15 (thermal ellipsoids drawn at the 50\% probability level).

that observed for ethylene. ${ }^{98}$ The ipso-carbon of the amidinate dianion is shifted upfield to $\delta 154.2$ from $\delta 172.8$ as observed for the monoanionic amidinates. X-ray diffraction studies revealed a dimeric structure where the thorium centers are bridged by the methylene carbon of the dianionic amidinate ligand (Fig. 9). Complex 15 crystallizes in $P \overline{1}$ with the asymmetric unit containing only the monomer unit; the dimer is generated through inversion symmetry. The $\mathrm{Th}(1)-\mathrm{C}(21)$ bond distance of $2.749(3)$ $\AA$ is significantly longer than the Th-C bond observed in 1 $(2.557(3) \AA)$, but shorter than the long Th- $\sigma$-alkyl bond distance of 2.875(9) $\AA$ observed by Liddle and co-workers in $\left[\mathrm{Th}\left\{\mathrm{N}\left(\mathrm{CH}_{2}-\right.\right.\right.$ $\left.\left.\left.\mathrm{CH}_{2} \mathrm{NSiMe}_{2}{ }^{t} \mathrm{Bu}\right)_{2}\left(\mathrm{CH}_{2} \mathrm{CH}_{2} \mathrm{NSiMe}{ }^{t} \mathrm{Bu}-\mu-\mathrm{CH}_{2}\right)\right\}\right]_{2}{ }^{{ }^{90}}$ The $\mathrm{C}(20)-$ $\mathrm{C}(21)$ bond distance of $1.438(4)$ is longer by $\sim 0.1 \AA$ than typically observed for $\mathrm{C}-\mathrm{C}$ double bonds, but this lengthening may be a result of delocalized electron density involved in the Th-C contact, reminiscent of a three-center two-electron bond. This is also manifested in the lack of planarity seen in the $-\mathrm{N}\left(\mathrm{CH}_{2}\right) \mathrm{CN}-$ unit of the amidinate dianion.

\section{Conclusions}

The amidinate-supported thorium monoalkyl complex $\mathbf{1}$ exhibits a variety of reactivity with small molecules, including insertion, protonolysis and photolysis. The insertion of $p$-tolyl azide lead to the thorium triazenido complex 3 which undergoes clean thermal decomposition at low concentrations to the corresponding amido complex $\mathbf{4}$, through the loss of the unstable " $\mathrm{N}_{2} \mathrm{CH}_{2}$ " fragment. This is the first example of an actinide complex undergoing this rare transformation. Insertion of xylyl isocyanide results in the first crystallographically characterized thorium iminoacyl complex. This insertion reactivity differs from that observed with $\mathrm{CO}$, which instead results in the corresponding enolate species 6 upon $\mathrm{CO}$ insertion and rearrangement, as well as the unique double $\mathrm{CO}$ insertion and amidinate cleavage product 7 . The utility of the alkyl moiety as an internal base was demonstrated with a variety of protic 
substrates, with the thorium phosphido complex 11a generated via both protonolysis and salt metathesis routes, the latter providing a more scalable option for the synthesis of 11a. The photolytic elimination of $\mathrm{SiMe}_{4}$ concomitant with the reduction of an amidinate ligand to form complex $\mathbf{1 5}$ is unprecedented reactivity with amidinate-supported metal complexes, and a rare example of a complex bearing a dianionic amidinate ligand. Mechanistic and reactivity investigations of several of the complexes reported are currently ongoing.

\section{Conflicts of interest}

There are no conflicts to declare.

\section{Acknowledgements}

This work was supported by the Director, Office of Science, Office of Basic Energy Sciences, Division of Chemical Sciences, Geosciences, and Biosciences Heavy Element Chemistry Program of the U.S. Department of Energy (DOE) at LBNL under Contract No. DE-AC02-05CH11231. We would like to acknowledge the NIH shared instrumentation grant S10-RR027172 for use in X-ray diffraction studies. N. S. S. acknowledges the Department of Energy Nuclear Energy University Programs for a graduate research fellowship. N. S. S. gratefully acknowledges Ms M. Garner, Mr M. Boreen and Mr T. Lohrey for their valuable discussions, and Mr P. Smith for assistance with the xenon arc lamp experiment.

\section{References}

1 C. J. Burns and M. S. Eisen, in The Chemistry of the Actinide and Transactinide Elements, ed. L. R. Morss, N. M. Edelstein and J. Fuge, Springer, Berlin, Heidelberg, 2006, vol. 5.

2 T. W. Hayton, Chem. Commun., 2013, 49, 2956-2973.

3 M. B. Jones and A. J. Gaunt, Chem. Rev., 2013, 113, 11371198.

4 S. T. Liddle, Angew. Chem., Int. Ed., 2015, 54, 2-40. 5 M. Ephritikhine, Organometallics, 2013, 32, 2464-2488.

6 A. R. Fox, S. C. Bart, K. Meyer and C. C. Cummins, Nature, 2008, 455, 341-349.

7 K. C. Jantunen, B. L. Scott and J. L. Kiplinger, J. Alloys Compd., 2007, 444, 363-368.

8 A. Yahia and L. Maron, Organometallics, 2009, 28, 672-679.

9 T. J. Marks and W. A. Wachter, J. Am. Chem. Soc., 1976, 98, 703-710.

10 D. G. Kalina, T. J. Marks and W. A. Wachter, J. Am. Chem. Soc., 1977, 99, 3877-3879.

11 J. W. Bruno, D. G. Kalina, E. A. Mintz and T. J. Marks, J. Am. Chem. Soc., 1982, 104, 1860-1869.

12 J. W. Bruno, T. J. Marks and V. W. Day, J. Am. Chem. Soc., 1982, 104, 7357-7360.

13 K. G. Moloy and T. J. Marks, J. Am. Chem. Soc., 1984, 106, 7051-7064.

14 J. W. Bruno, G. M. Smith, T. J. Marks, C. K. Fair, A. J. Schultz and J. M. Williams, J. Am. Chem. Soc., 1986, 108, 40-56.
15 K. G. Moloy, P. J. Fagan, J. M. Manriquez and T. J. Marks, J. Am. Chem. Soc., 1986, 108, 56-67.

16 W. J. Evans, J. R. Walensky, J. W. Ziller and A. L. Rheingold, Organometallics, 2009, 28, 3350-3357.

17 K. C. Jantunen, C. J. Burns, I. Castro-Rodriguez, R. E. Da Re, J. T. Golden, D. E. Morris, B. L. Scott, F. L. Taw and J. L. Kiplinger, Organometallics, 2004, 23, 4682-4692.

18 J. A. Pool, B. L. Scott and J. L. Kiplinger, J. Am. Chem. Soc., 2005, 127, 1338-1339.

19 R. J. Butcher, D. L. Clark, S. K. Grumbine, B. L. Scott and J. G. Watkin, Organometallics, 1996, 15, 1488-1496.

20 E. J. Schelter, P. Yang, B. L. Scott, R. E. Da Re, K. C. Jantunen, R. L. Martin, P. J. Hay, D. E. Morris and J. L. Kiplinger, J. Am. Chem. Soc., 2007, 129, 5139-5152.

21 C. A. Cruz, D. J. H. Emslie, L. E. Harrington, J. F. Britten and C. M. Robertson, Organometallics, 2007, 26, 692-701.

22 C. A. Cruz, D. J. H. Emslie, L. E. Harrington and J. F. Britten, Organometallics, 2008, 27, 15-17.

23 C. A. Cruz, D. J. H. Emslie, C. M. Robertson, L. E. Harrington, H. A. Jenkins and J. F. Britten, Organometallics, 2009, 28, 1891-1899.

24 B. M. Gardner, P. A. Cleaves, C. E. Kefalidis, J. Fang, L. Maron, W. Lewis, A. J. Blake and S. T. Liddle, Chem. Sci., 2014, 5, 2489-2497.

25 L. A. Seaman, J. R. Walensky, G. Wu and T. W. Hayton, Inorg. Chem., 2013, 52, 3556-3564.

26 A. C. Behrle, A. J. Myers, P. Rungthanaphatsophon, W. W. Lukens, C. L. Barnes and J. R. Walensky, Chem. Commun., 2016, 52, 14373-14375.

27 M. Suvova, K. T. P. O'Brien, J. H. Farnaby, J. B. Love, N. Kaltsoyannis and P. L. Arnold, Organometallics, 2017, 36, 4669-4681.

28 E. Mora, L. Maria, B. Biswas, C. Camp, I. C. Santos, J. Pécaut, A. Cruz, J. M. Carretas, J. Marçalo and M. Mazzanti, Organometallics, 2013, 32, 1409-1422.

29 T. D. Lohrey, R. G. Bergman and J. Arnold, Angew. Chem., Int. Ed., 2017, 56, 14241-14245.

30 S. Hohloch, M. E. Garner, B. F. Parker and J. Arnold, Dalton Trans., 2017, 46, 13768-13782.

31 J. A. Ziegler, H. L. Buckley and J. Arnold, Dalton Trans., 2017, 46, 780-785.

32 M. E. Garner, S. Hohloch, L. Maron and J. Arnold, Organometallics, 2016, 35, 2915-2922.

33 C. Camp, N. Settineri, J. Lefevre, A. R. Jupp, J. M. Goicoechea, L. Maron and J. Arnold, Chem. Sci., 2015, 6, 6379-6384.

34 M. A. Boreen, B. F. Parker, T. D. Lohrey and J. Arnold, J. Am. Chem. Soc., 2016, 138, 15865-15868.

35 N. S. Settineri, M. E. Garner and J. Arnold, J. Am. Chem. Soc., 2017, 139, 6261-6269.

36 T. Cantat, B. L. Scott and J. L. Kiplinger, Chem. Commun., 2010, 46, 919-921.

37 S. Hao, S. Gambarotta, C. Bensimon and J. J. H. Edema, Inorg. Chim. Acta, 1993, 213, 65-74.

38 R. R. Langeslay, M. E. Fieser, J. W. Ziller, F. Furcher and W. J. Evans, Chem. Sci., 2015, 6, 517-521.

39 T. Kurogi, M. V. Mane, S. Zheng, P. J. Carroll, M. Baik and D. J. Mindiola, Angew. Chem., Int. Ed., 2018, 57, 1978-1981. 
40 R. Hoffmann, R. Gleiter and F. B. Mallory, J. Am. Chem. Soc., 1970, 92, 1460-1466.

41 R. Waterman and G. L. Hillhouse, J. Am. Chem. Soc., 2003, 125, 13350-13351.

42 S. J. Kraft, P. E. Fanwick and S. C. Bart, Organometallics, 2013, 32, 3279-3285.

43 Y. Yu, A. R. Sadique, J. M. Smith, T. R. Dugan, R. E. Cowley, W. W. Brennessel, C. J. Flaschenriem, E. Bill, T. R. Cundari and P. L. Holland, J. Am. Chem. Soc., 2008, 130, 6624-6638.

44 E. Zhou, W. Ren, G. Hou, G. Zi, D.-C. Fang and M. D. Walter, Organometallics, 2015, 34, 3637-3647.

45 M. G. Thorn, J. Lee, P. E. Fanwick and I. P. Rothwell, J. Chem. Soc., Dalton Trans., 2002, 17, 3398-3405.

46 M. Nechayev, T. L. Gianetti, R. G. Bergman and J. Arnold, Dalton Trans., 2015, 44, 19494-19500.

47 F. Amor, A. Butt, K. E. du Plooy, T. P. Spaniol and J. Okuda, Organometallics, 1998, 17, 5836-5849.

48 R. Fandos, A. Otero, A. M. Rodriguez and S. Suizo, Organometallics, 2012, 31, 1849-1856.

49 W. J. Evans, M. K. Takase, J. W. Ziller and A. L. Rheingold, Organometallics, 2009, 28, 5802-5808.

50 N. A. Siladke, J. W. Ziller and W. J. Evans, J. Am. Chem. Soc., 2011, 133, 3507-3516.

51 W. J. Evans, J. R. Walensky and J. W. Ziller, Organometallics, 2010, 29, 945-950.

52 W. J. Evans, N. A. Siladke and J. W. Ziller, Chem.-Eur. J., 2010, 16, 796-800.

53 W. Ren, G. Zi, D.-C. Fang and M. D. Walter, J. Am. Chem. Soc., 2011, 133, 13183-13196.

54 D. M. Barnhart, D. L. Clark, J. C. Gordon, J. C. Huffman and J. G. Watkin, Inorg. Chem., 1994, 33, 3939-3944.

55 J. L. Kiplinger, B. L. Scott, E. J. Schelter and J. A. P. D. Tournear, J. Alloys Compd., 2007, 444, 477-482.

56 D. L. Clark and J. G. Watkin, Inorg. Chem., 1993, 32, 17661772.

57 C. M. Fendrick, E. A. Mintz, L. D. Schertz and T. J. Marks, Organometallics, 1984, 3, 819-821.

58 S. J. Simpson and R. A. Andersen, J. Am. Chem. Soc., 1981, 103, 4063-4066.

59 J. M. Manriquez, P. J. Fagan, T. J. Marks, C. S. Day and V. W. Day, J. Am. Chem. Soc., 1978, 100, 7112-7114.

60 O. Bénaud, J.-C. Berthet, P. Thuéry and M. Ephritikhine, Inorg. Chem., 2010, 49, 8117-8130.

61 P. L. Arnold, Z. R. Turner, A. I. Germeroth, I. J. Casely, G. S. Nichol, R. Bellabarba and R. P. Tooze, Dalton Trans., 2013, 42, 1333-1337.

62 K. Tatsumi, A. Nakamura, P. Hofmann, R. Hoffmann, K. G. Moloy and T. J. Marks, J. Am. Chem. Soc., 1986, 108, 4467-4476.

63 N. S. Radu, M. P. Engeler, C. P. Gerlach, T. D. Tilley and A. L. Rheingold, J. Am. Chem. Soc., 1995, 117, 3621-3622.

64 D. Cui, M. Nishiura and Z. Hou, Angew. Chem., Int. Ed., 2005, 44, 959-962.

65 F. G. Bordwell and D. J. Algrim, J. Am. Chem. Soc., 1988, 110, 2964-2968.

66 F. G. Bordwell, Acc. Chem. Res., 1988, 21, 456-463.
67 O. T. Beachley Jr, D. J. MacRae and A. Y. Kovalevsky, Organometallics, 2003, 22, 1690-1695.

68 D. A. Wrobleski, R. R. Ryan, H. J. Wasserman, K. V. Salazar, R. T. Paine and D. C. Moody, Organometallics, 1986, 5, 90-94.

69 S. W. Hall, J. C. Huffman, M. M. Miller, L. R. Avens, C. J. Burns, D. S. J. Arney, A. F. England and A. P. Sattelberger, Organometallics, 1993, 12, 752-758.

70 M. E. Garner and J. Arnold, Organometallics, 2017, 36, 45114514.

71 R. Waterman, Organometallics, 2007, 26, 2492-2494.

72 A. C. Behrle, L. Castro, L. Maron and J. R. Walensky, J. Am. Chem. Soc., 2015, 137, 14846-14849.

73 E. P. Wildman, G. Balázs, A. J. Wooles, M. Scheer and S. T. Liddle, Nat. Commun., 2016, 7, 12884-12895.

74 M. R. Duttera, V. W. Day and T. J. Marks, J. Am. Chem. Soc., 1984, 106, 2907-2912.

75 M. E. Garner, B. F. Parker, S. Hohloch, R. G. Bergman and J. Arnold, J. Am. Chem. Soc., 2017, 139, 12935-12938.

76 J.-C. Hierso, V. V. Ivanov, R. Amardeil, P. Richard and P. Meunier, Chem. Lett., 2004, 33, 1296-1297.

77 A. Marchenko, A. Hurieva, H. Koidan, V. Rampazzi, H. Cattey, N. Pirio, A. N. Kostyuk and J.-C. Hierso, Organometallics, 2012, 31, 5986-5989.

78 J.-C. Hierso, Chem. Rev., 2014, 114, 4838-4867.

79 A. C. Behrle and J. R. Walensky, Dalton Trans., 2016, 45, 10042-10049.

80 A. Haskel, T. Straub, A. K. Dash and M. S. Eisen, J. Am. Chem. Soc., 1999, 121, 3014-3024.

81 A. K. Dash, J. Q. Wang and M. S. Eisen, Organometallics, 1999, 18, 4724-4741.

82 I. Pappas and P. J. Chirik, Angew. Chem., Int. Ed., 2014, 53, 6241-6244.

83 S. K. Podiyanachari, R. Fröhlich, C. G. Daniliuc, J. L. Petersen, C. Mück-Lichtenfeld, G. Kehr and G. Erker, Angew. Chem., Int. Ed., 2012, 51, 8830-8833.

84 T. P. Vaid, A. S. Veige, E. B. Lobkovsky, W. V. Glassey, P. T. Wolczanski, L. M. Liable-Sands, A. L. Rheingold and T. R. Cundari, J. Am. Chem. Soc., 1998, 120, 10067-10079.

85 J. R. Walensky, R. L. Martin, J. W. Ziller and W. J. Evans, Inorg. Chem., 2010, 49, 10007-10012.

86 J.-C. Berthet, C. Villiers, J.-F. Le Maréchal, B. Delavaux-Nicot, M. Lance, M. Nierlich, J. Vigner and M. Ephritikhine, J. Organomet. Chem., 1992, 440, 53-65.

87 N. E. Travia, M. J. Monreal, B. L. Scott and J. L. Kiplinger, Dalton Trans., 2012, 41, 14514-14523.

88 A. C. Behrle, J. R. Levin, J.-E. Kim, J. M. Drewett, C. L. Barnes, E. J. Schelter and J. R. Walensky, Dalton Trans., 2015, 44, 2693-2702.

89 A. Zalkin, D. H. Templeton, C. Le Vanda and A. Streitwieser Jr, Inorg. Chem., 1980, 19, 2560-2563.

90 B. M. Gardner, W. Lewis, A. J. Blake and S. T. Liddle, Organometallics, 2015, 34, 2386-2394.

91 J. A. Soderquist and M. R. Najafi, J. Org. Chem., 1986, 51, 1330-1336.

92 G. R. Eaton, J. Chem. Educ., 1969, 46, 547-556.

93 R. Shinomoto, E. Gamp, N. M. Edelstein, D. H. Templeton and A. Zalkin, Inorg. Chem., 1983, 22, 2351-2355. 
$94 \mathrm{H}$. W. Turner, R. A. Andersen, A. Zalkin and D. H. Templeton, Inorg. Chem., 1979, 18, 1221-1224.

95 J. McKinven, G. S. Nichol and P. L. Arnold, Dalton Trans., 2014, 43, 17416-17421.

96 T. M. Trnka, J. B. Bonanno, B. M. Bridgewater and G. Parkin, Organometallics, 2001, 20, 3255-3264.
97 S. R. Daly, P. M. B. Piccoli, A. J. Schultz, T. K. Todorova, L. Gagliardi and G. S. Girolami, Angew. Chem., Int. Ed., 2010, 49, 3379-3381.

98 J. Kaski, P. Lantto, J. Vaara and J. Jokisaari, J. Am. Chem. Soc., 1998, 120, 3993-4005. 